\title{
Perancangan Maskot untuk Memperkuat Identitas Visual Kota Kediri
}

\author{
Ferdian Lutfi Kurniawan dan Sayatman \\ Departemen Desain Produk, Fakultas Arsitektur, Desain, dan Perencanaan, \\ Institut Teknologi Sepuluh Nopember (ITS) \\ e-mail: sayatasik@prodes.its.ac.id
}

\begin{abstract}
Abstrak-Pada tahun 2014, pemerintah Kota Kediri melakukan penelitian untuk mencari potensi daerahnya. Hasilnya, Kota Kediri memiliki potensi utama pada tiga sektor yaitu pendidikan, jasa dan perdagangan. Sebagai upaya meningkatkan potensi dan citra kotanya, pada tahun 2016 pemerintah Kota Kediri meluncurkan program city branding bertajuk "Harmoni Kediri". Namun, berdasarkan hasil kajian pengurus brand kota Kediri, hingga saat ini masyarakat belum familiar terhadap keberadaan identitas Kota Kediri tersebut. Penelitian ini mengkaji tentang peran maskot untuk meningkatan kekuatan identitas visual kota. Proses penelitian ini terbagi menjadi dua tahap yaitu tahap pra riset yang mengkaji tentang dasar penggunaan tema judul dan tahap riset yang mengkaji tentang obyek dan media perancangan. Sumber data primer dihasilkan dari wawancara dengan pengurus brand, observasi, wawancara dengan calon audiens, eksperimen visual, uji karakter melalui kuesioner visual, sedangkan sumber data sekunder diperoleh dari studi pustaka keilmuan identitas, desain karakter, dan studi karakter yang sudah ada sebelumnya. Luaran media perancangan ini adalah konsep desain identitas visual berupa karakter maskot yang merepresentasikan Kota Kediri. Konsep komunikasi karakter dibagi menjadi tiga tahap. Tahap pertama sebelum kedatangan pengunjung, tahap kedua ketika pengunjung datang ke kota, tahap ketiga ketika pengunjung hendak meninggalkan kota. Desain maskot ini diharapkan dapat membantu program pemerintah Kota Kediri dalam menguatkan identitas visual kota yang kuat di mata masyarakat.
\end{abstract}

Kata Kunci-City Branding, Harmoni Kediri, Identitas, Kota Kediri.

\section{PENDAHULUAN}

$\mathrm{K}$ OTA KEDIRI merupakan satu dari 38 kabupatan/kota di Jawa Timur. Kota ini terletak $130 \mathrm{~km}$ sebelah barat daya Kota Surabaya. Kota ini memiliki luas $63,40 \mathrm{~km}^{2}$ dan seluruh wilayahnya berbatasan dengan Kabupaten Kediri. Kota Kediri lebih dikenal sebagai pusat jasa dan perdagangan. Hal ini dibuktikan oleh kegiatan utama Kota Kediri pada berbagai sektor, yaitu sektor industri, pendidikan, perdagangan. Dan pada tahun 2016, pemerintah kota mengenalkan city branding yang bertajuk "Harmoni Kediri". Melalui program tersebut diharapkan seluruh elemen Kota Kediri memberikan kemudahan dan pelayanan terbaik untuk masyarakatnya.. Namun, berdasarkan hasil kajian pengurus brand, masyarakat belum familiar terhadap keberadaan identitas Kota Kediri.

Untuk menSatu dari berbagai cara untuk menumbuhkan brand experience adalah memberikan stimulus terkait brand seperti warna, bentuk, tipografi,desain, slogan, maskot, dan karakter brand. Sedangkan maskot sendiri merupakan antropomorfisme, ialah atribusi karakteristik manusia ke mahkluk bukan manusia. Seperti binatang yang mempunyai sifat dan motivasi seperti manusia [1]. Ketika subyek antropomorfisme itu berinteraksi dengan manusia, maka dapat menimbulkan ketertarikan manusia. Oleh karena itu, sebuah maskot sering kali digunakan sebagi media promosi pada produk maupun jasa.

Beberapa kota lain yang sudah memiliki maskot sebagai pendukung city branding adalah Kota Batu dengan maskotnya si Osi \& Ji dan Kota Surabaya dengan Cak Suro dan Cak Boyo. Kedua kota ini termasuk kota besar di Jawa Timur dan sudah memiliki karakter maskot resmi. Oleh karena itu, penulis merancang sebuah maskot sebagai media pendukung identitas Kota Kediri. Hasil perancangan ini diharapkan dapat membantu pemerintah Kota Kediri dalam menguatkan identitas visual kotanya.

\section{URAIAN PENELITIAN}

\section{A. Maskot}

Maskot adalah orang, hewan, yang memiliki sifat seperti manusia dan dianggap dapat membawa keberuntungan dan merepresentasikan identitas organisasi, produk, tim olahraga dan lain-lain. Maskot yang baik adalah maskot yang ikonik dan fleksibel.

\section{B. Desain Karakter}

Sebuah karakter harus memunyai biodata. biodata tersebut akan memberikan gambaran tentang siapa karakternya, bagaimana penampilannya, apa kesukaannya dan yang apa yang ia benci, bagaimana perilakunya, apa fitur pembedanya, dan karakter emosional [2].

\section{Arketipe}

Seorang psikolog asal Swiss yang bernama Carl Gustav Jung berpendapat bahwa setiap orang memiliki ciri kepribadian yang berbeda dan membentuk pola dasar yang disebut Arketipe [3]. Terdapat 12 Arketipe sebagai acuan membuat karakter maskot, yaitu sebagai berikut : The Innocent,The Orphan, The Hero,The Cargiver, The Explorer, The Rebel, The Lover,The Creator,The Jester, The Sage, The Magician, The Ruler. 


\section{Identitas}

Alina Wheeler dalam Designing Brand Identity menyebutkan idealisme dalam membentuk identitas, yaitu : Vision, Meaning, Authenticity, Differentiation, Durabelty, Coherence, Flexibility, Commitment, Value. Ide-ide diatas membantu desainer dalam membentuk sebuah identitas [4].

\section{METODE PENELITIAN}

Dalam perancangan maskot ini, perancang menggunakan metodologi pengumpulan data primer dan sekunder. Data sekunder diperoleh dari studi pustaka, atau dari data-data yang sudah tersedia di publik seperti internet, data pemerintah nasional/lokal, dan dari internet yang terpercaya sumbernya.

\section{A. Data Primer}

Peneliti mengumpulkan data primer dengan cara :

a. Depth Interview dengan Ketua Pengurus Brand Harmoni Kediri ialah Ibu Herwin Zakiyah, S.T., M.Eng. di Bagian Humas Pemkot Kota Kediri.

b. Observasi penulis melakukan eksplorasi/menjelajah potensi-potensi di Kota Kediri yang menarik untuk dijadikan inspirasi maskot. Penulis mengunjungi 6 tempat : Pusat Oleh-oleh tahu Kediri, Patung Macan Putih, Kebun Bunga Matahari, Sentra UKM Ikan Cupang, dan Kesenian Jaranan.

c. Survei pemilihan maskot kepada masyarakat Kota Kediri.

$d$. Menyebarkan kuisioner on-line yang disebar untuk warga Kota Kediri untuk mengambil keputusan desain maskot yang paling banyak disukai.

e. Eksperimental Visual dengan cara mengukur efek visual suatu variabel tidak tetap terhadap variable tetap.

f. Uji Karakter kepada 51 responden dengan kuisioner visual untuk memeroleh penilaian masyarakat terhadap karakter.

g. Melakukan desain ulang karakter dikarenakan adanya beberapa penilaian yang kurang sesuai.

\section{B. Data Sekunder}

Penelitian ini mendapkan sumber-sumber data sekunder dari studi literatur dan studi karakter yang sudah ada dan dinilai berhasil. Diantaranya :

a. Studi Literatur : Maskot, Desain Karakter, Identitas, Sejarah dan profil Kota Kediri dan pengetahuan tentang standar brand Kota Kediri.

b. Studi Eksisting : Maskot Kumamon, Maskot Olimpiade 2016 Vinicius de Moraes dan Mickey Mouse.

\section{KONSEP}

Konsep merupakan draft produk atau luaran produk yang dihasilkan perancangan ini. Konsep menjawab solusi dari masalah yang sudah dirumaskan. Konsep ini terbagi menjadi 2 aspek : Konsep Visual Karakter Maskot dan Konsep Media
Interaktif.

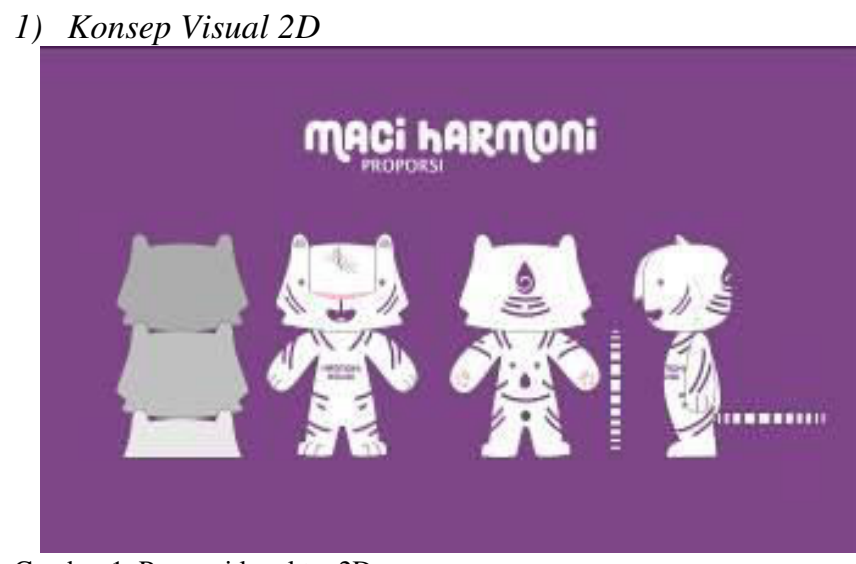

Gambar 1. Proporsi karakter 2D.

2) Konsep Visual $3 D$

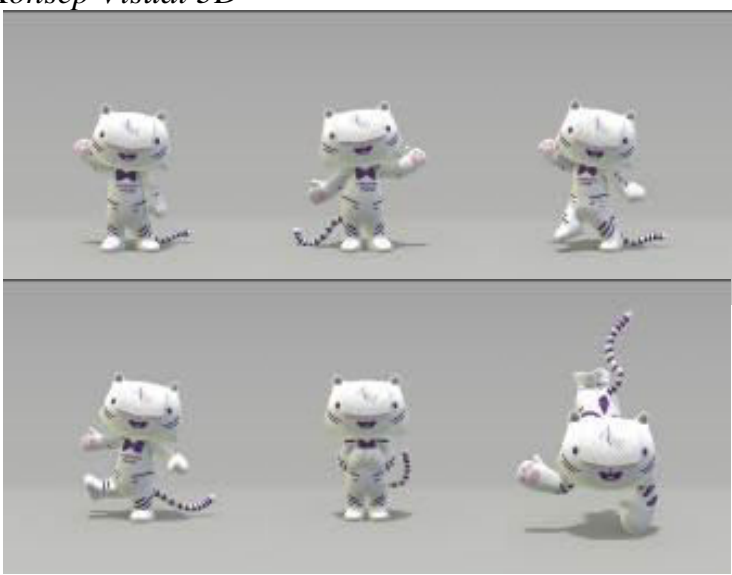

Gambar 2. Karakter 3D.

3) Konsep Tipografi

Tipografi Maci Harmoni menggunakan font Roundly Rainbow karena ada kesamaan bentukan ekor antara ekor Maci dan beberapa huruf font.
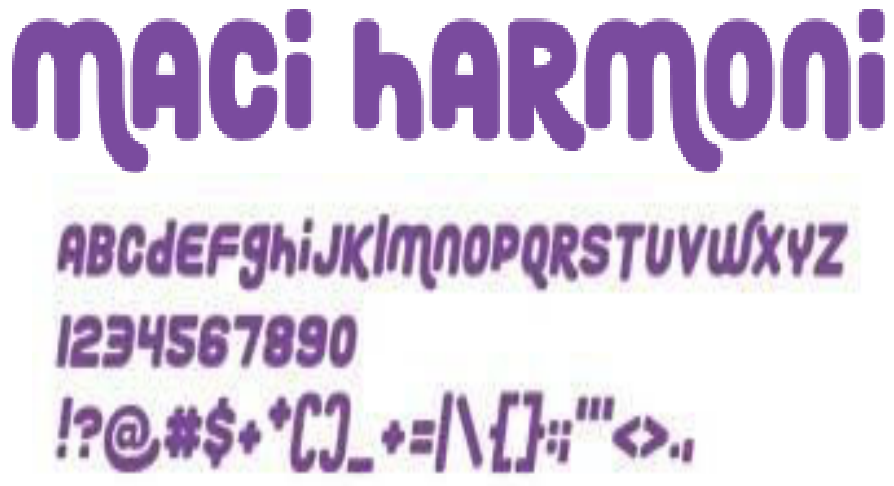

Gambar 3. Tipografi Maskot. 


\section{4) Aktifitas Maci Harmoni}
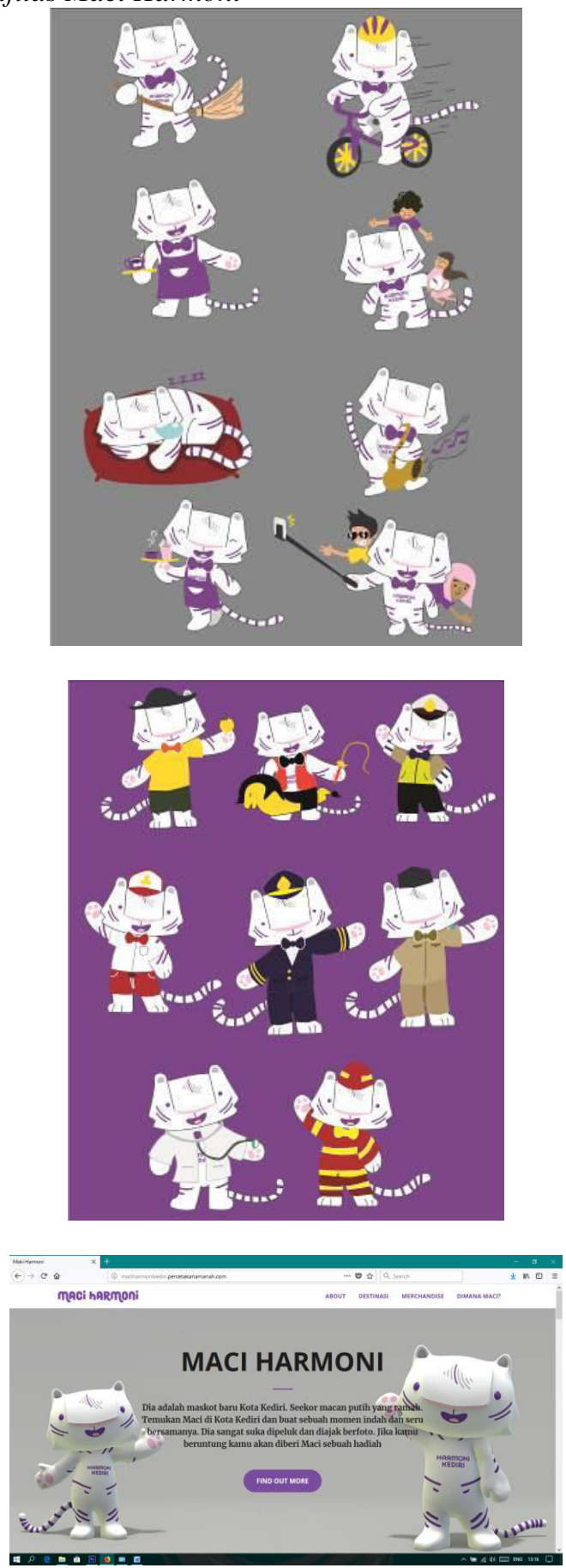

Gambar 4. Aktifitas MACI Harmoni.

\section{5) Konsep Media}

Berdasarkan riset media yang sering diakses atau dekat dengan audiens yang mana adalah traveler yang suka jalanjalan. Luaran media dibagi berdasarkan 3 tahap, yaitu :

a. Tahap sebelum kedatangan pengunjung : Website, Video Bumper, Media Sosial

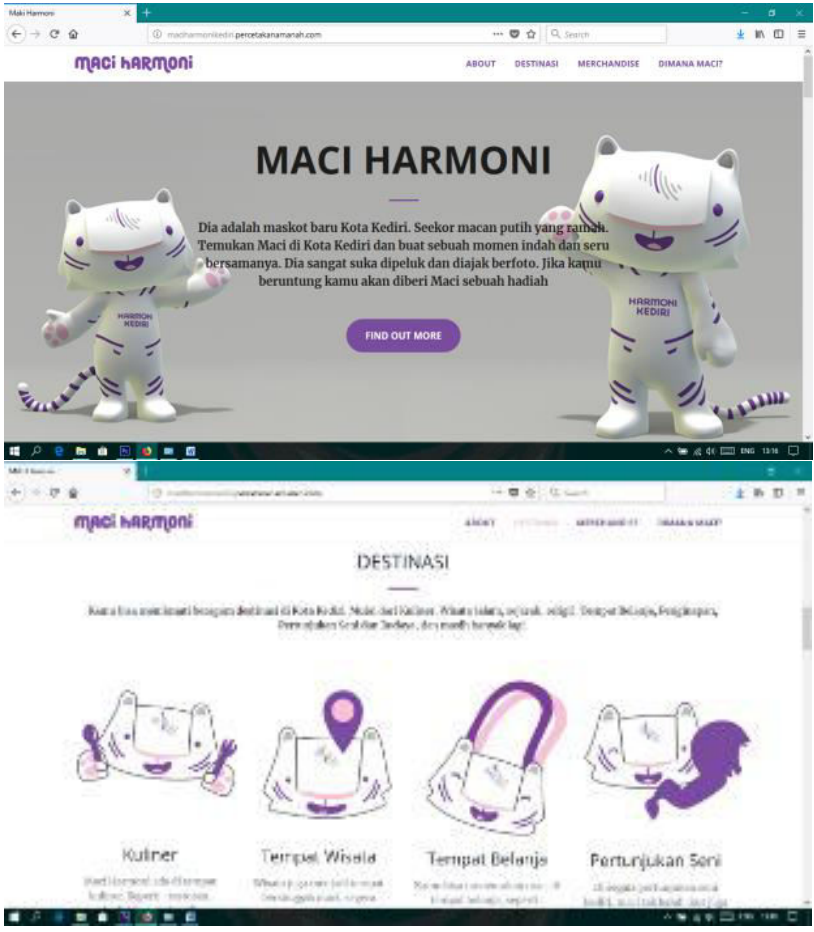

Gambar 5. Website Maci Harmoni.

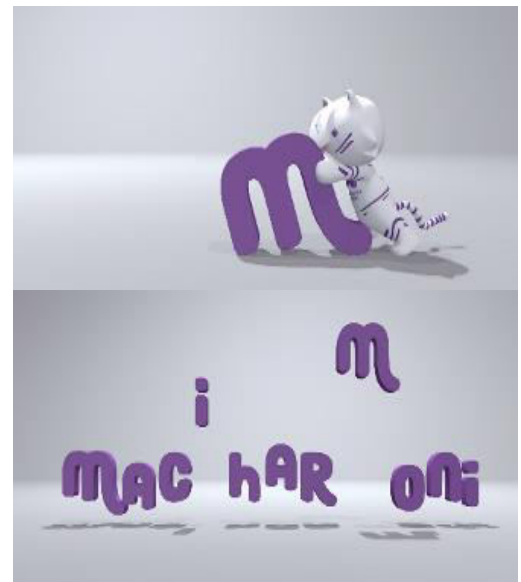

Gambar 6. Animasi bumper.

b. Saat Kedatangan : Patung Maskot, Mural tembok dan transportasi umum. Media ini ada disekitar masyarakat kota seperti di taman, angkutan umum, dan ditengahtenagah kota.

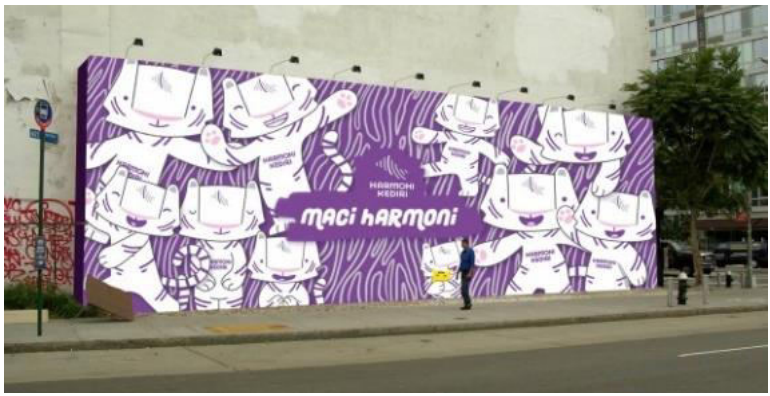

Gambar 7. Mural. 


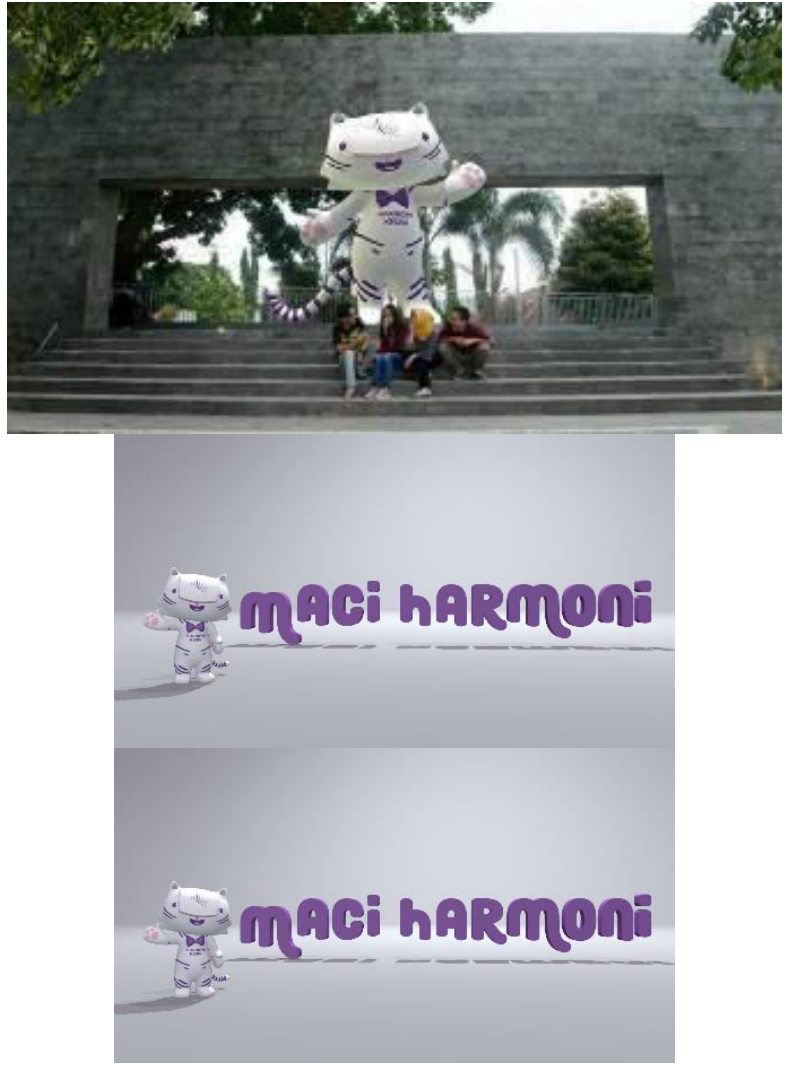

Gambar 8. Patung maskot di taman kota.

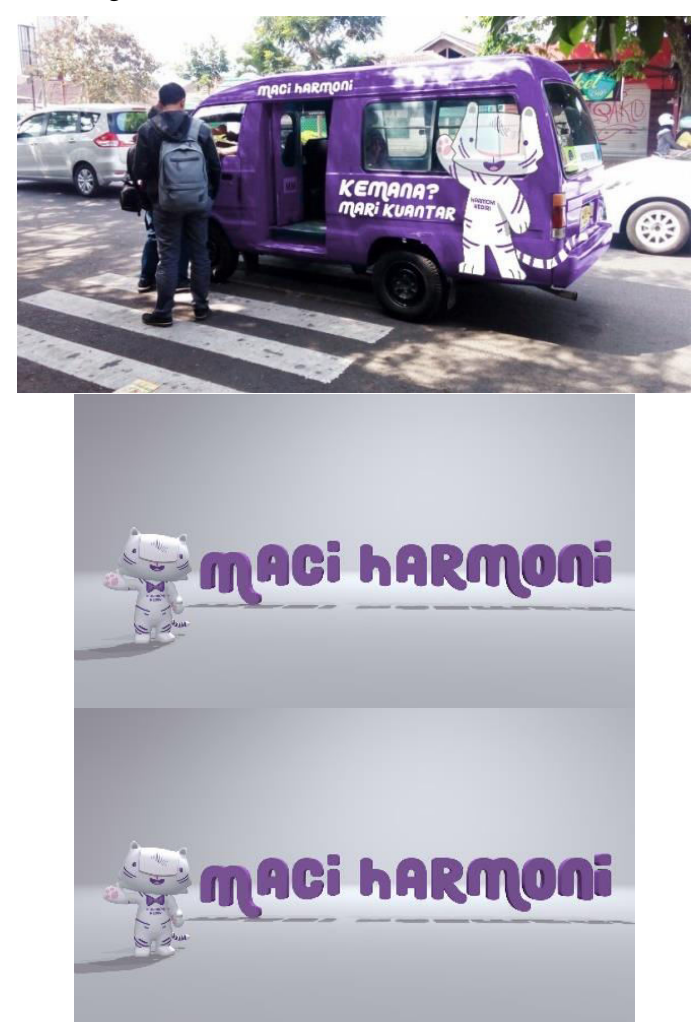

Gambar 9. Sticker maskot di angkutan umum.

c. Akhir Kunjungan : Kaos, Pin, Gantungan Kunci, Booknote. Kemasan Kue Maci diperuntukkan bagi wisatawan yang dating ke Kota Kediri sebagai cinderamata.
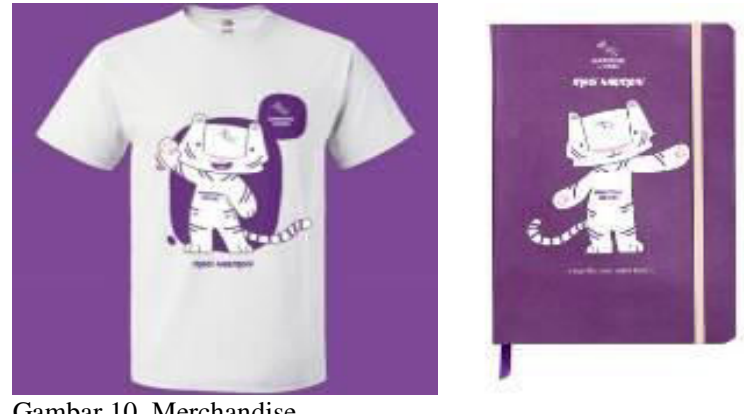

Gambar 10. Merchandise.

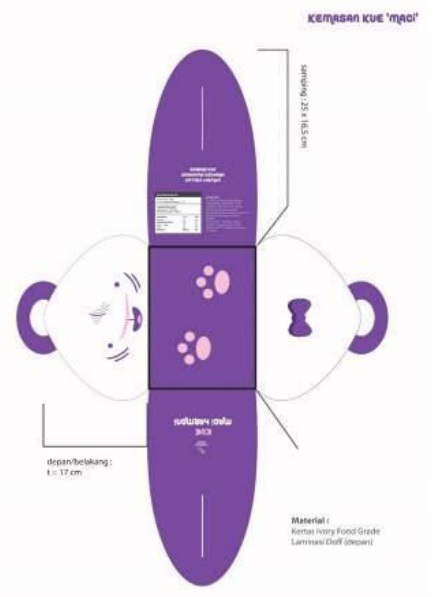

Gambar 11. Desain Kemasan Kue Maci Harmoni.

1. Media Konvensional

Media-media konvensional seperti billboard, banner, dan baliho tidak memungkiri juga dibutuhkan karena biaya yang murah dan menjangkau orang-orang di jalan.

2. Konsep Strategi Pengenalan Maci Harmoni
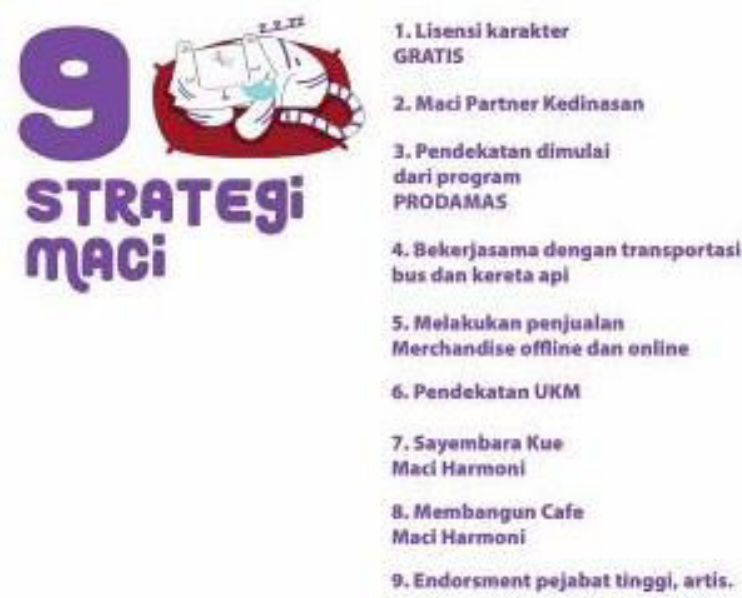

Gambar 12. Pengenalan Maci Harmoni.

a. Lisensi Karakter Gratis

Karakter Maci Harmoni tetap memiliki lisensi akan tetapi tetap menggratiskan pemakaian karakter ini untuk semua warga Kota Kediri.

b. Maci Partner Kediasan

Ada beberapa dinas di pemkot Kediri, masingmasing diberikan modal grafis karakter Maci Harmoni. Dengan maksud masing-masing dinas menempelkan karakter Maci di setiap media komunikasi atau promosi masing-masing dinas. 
c. Pendekatan dengan PRODAMAS

Dalam program ini Maci Harmoni oleh pemerintah kota menjadikan syarat pembangunan kampung harus membubuhkan gambar karakter Maci Harmoni sebagai bagian dari hiasan di kampung mereka dengan spesifikasi tinggi gambar minimal 1 meter.

d. Bekerjasama dengan transportasi bus dan kereta api Agar Maci Harmoni dikenal banyak orang baik di dalam maupun diluar, pendekatan yang harus dilakukan adalah menampilkan Maci pada transportasi.

e. Menjual merchandise secara offline dan online

Setelah keberadaan maskot Maci Harmoni di ketahui orang banyak baik di dalam maupun diluar kota, direncanakan membuat sebuah toko merchandise Maci Harmoni.

f. Pendekatn dengan UKM-UKM di Kota Kediri

Penulis menyarankan agar pemerintah yang bersangkutan memberikan keringanan pajak bagi UKM yang membubuhkan karakter Maci Harmoni di kemasan produk mereka.

g. Membangun Maci Cafe

Setelah Maci Harmoni memiliki produk sendiri berupa kue. Strategi selanjutnya adalah membangun Maci Cafe. Kebiasaan anak muda yang gemar nongkrong di cafe akan dimanfaatkan sebagai strategi mengenalkan dan menguatkan identitas Harmoni Kediri.

h. Membangun Maci Café

Produk-produk yang sudah ada di endorsmen ke pejabat tinggi dan artis untuk dipromosikan baik dari mulut-kemulut maupun akun social media mereka.

\section{KESIMPULAN/RINGKASAN}

Maskot Maci Harmoni mampu memperkuat identitas Harmoni Kediri. Hal ini dikarenakan personifikasi maskot mampu bembuat audiens memiliki pengalaman bersama brand. Selain itu media maskot juga dapat dipergunakan sebagai promosi kota.

\section{DAFTAR PUSTAKA}

[1] Anonymous, "Mas Abu Potensi Kota Kediri sebagai Ibu Kota Pendidikan harus terus didorong," pankotakediri.com, 2017. .

[2] B. Tillman, "Creative Character Design," pp. 11-12.

[3] D. van Hoolwerff, Does Your Mascot Match Your Brand's Personality? University of Twente, 2014.

[4] W. Alina, Designing Brand Identity, Hoboken. New Jersey: John Wiley \& Sons Inc, 2009. 